\title{
Membrane Protein Lesions in Erythrocytes with Heinz Bodies
}

\author{
Orah S. Platt and Jill F. Falcone \\ Department of Pediatrics, Harvard Medical School, Division of Hematology and Oncology, \\ Children's Hospital and Dana-Farber Cancer Institute, Boston, Massachusetts 02115
}

\begin{abstract}
We studied Heinz body-containing erythrocytes with three different unstable hemoglobins: Nottingham, Brockton, and unclassified. We demonstrated two classes of membrane protein defects in unstable hemoglobin-containing cells (UHRBCs), a defect of the spectrin-depleted inside-out vesicle (UH-IOV), and a defect of spectrin (UH-spectrin) itself.

The composition of UH-IOVs is the same as control with respect to quantity of ankyrin and proportion inside-out. However, UH-IOVs bind even less spectrin than IOVs derived from sickle erythrocytes (SS-IOVs), suggesting a severe functional defect in the ankyrin of UH-RBCs (UH-ankyrin). Further evidence that UH-ankyrin is abnormal is demonstrated by the virtual absence of ankyrin in isotonic membrane shells of UH-RBCs (UH-shells), and abnormal mobility and decreased binding of the 72-kD (spectrin-binding) $\alpha$-chymotryptic fragment of UH-ankyrin (UH-72-kD) to control spectrin.

All UH-RBC membranes were spectrin-deficient (60\% of control). In addition, spectrin isolated from UH-RBCs (UHspectrin) was abnormal in two respects: (a) presence of a fastmoving band on nondenaturing polyacrylamide gels of both $0^{\circ} \mathrm{C}$ and $37^{\circ} \mathrm{C}$ extracts, and $(b)$ decreased binding to actin in the presence of protein 4.1. UH-spectrin did exhibit normal self-association, binding to IOVs and binding to actin in the absence of protein 4.1. This pattern of normal and abnormal spectrin functions has been described for spectrin subjected to mild diamide oxidation, suggesting the role of oxidation is the pathogenesis of membrane defect(s) of erythrocytes with abnormal hemoglobins.
\end{abstract}

\section{Introduction}

The inner surface of the erythrocyte membrane incubates in a concentrated hemoglobin solution $(300 \mathrm{mg} / \mathrm{ml})$ throughout the 120-d life of the cell. At these concentrations, hemoglobin interacts with membrane proteins, binds to the cytoplasmic domain of protein $3(1-8)$, and stabilizes the self-association of spectrin, the major structural protein of the membrane skeleton (9). The modification of the erythrocyte membrane by abnormal hemoglobins is emerging as an important theme in the attempt to understand the pathophysiology of membrane damage in hemoglobinopathies and the process of erythrocyte senescence $(10-17)$.

Portions of this work have been published in abstract form (1984. Blood. 64:30a; and 1985. Blood. 66:37a).

Address reprint requests to Dr. Platt, Children's Hospital, 300 Longwood Avenue, Boston, MA 02115. 1988.

Received for publication 3 April 1986 and in revised form 21 March

J. Clin. Invest.

(c) The American Society for Clinical Investigation, Inc.

0021-9738/88/09/1051/08 $\$ 2.00$

Volume 82, September 1988, 1051-1058
We have studied the function of structural proteins of erythrocytes from patients with homozygous sickle cell anemia (SS-RBC) ${ }^{1}$ and have demonstrated decreased binding of normal spectrin to its high-affinity binding site (ankyrin) on inside-out vesicles from patients with homozygous sickle cell anemia (SS-IOVs) (10). Although this binding defect is not reversible by reduction with dithiothreitol (DTT), we suspect that it is an oxidative lesion caused by oxygen radicals which have been demonstrated by Hebbel and colleagues to be generated in excess in SS-RBCs (18). In fact, Rank and co-workers (19) have shown (using thiol-disulfide exchange chromatography) that SS-RBCs do contain increased amounts of oxidized membrane proteins, including ankyrin (19).

In an attempt to dissect the pathogenesis of the membrane damage in SS-RBCs, we examined membrane protein function in other pathological erythrocytes which are exposed to oxidation, but not sickling. We looked specifically at Heinz body-containing unstable hemoglobin-containing erythrocytes (UH-RBCs) and erythrocytes treated with acetylphenyl hydrazine (APH-RBCs).

Unstable hemoglobin Koln erythrocyte membranes have been well documented by Flynn and colleagues to exhibit evidence of lipid and protein oxidation (20), and have increased protein thiol oxidation analagous to SS-RBCs as measured by Rank et al. (19). Superoxide anion is readily produced by the autoxidation of hemoglobin Koln, a reaction which is favored in this intrinsically "unstable" hemoglobin because of its abnormal tertiary structure, a result of an amino acid substitution near the stabilizing heme pocket $\left({ }^{\beta} 98\right.$; Val $\rightarrow$ Met). Such autoxidant-prone unstable tertiary structure is present in our patient with another heme pocket abnormality, hemoglobin Nottingham ( ${ }^{\beta} 98$; Val $\rightarrow$ Gly), and in our patient with hemoglobin Brockton, in. which the alpha helix is disrupted by the presence of an aberrent proline ( ${ }^{\beta} 138$; Ala $\rightarrow$ Pro). The biochemical lesion in our patient with the unclassified hemoglobin is not known.

Acetylphenylhydrazine, phenylhydrazine, and hydrazine generate Heinz bodies and activated oxygen radicals within erythrocytes (21), and cause oxidation of membrane lipids and proteins $(22,23)$. Waugh and Low (12) and Low and colleagues (13) have focused on phenylhydrazine-induced hemoglobin oxidation to hemichrome, and its binding to and modulation of the organization of protein $3(12,13)$, a feature that is also found in SS-RBCs (16). Here we examine the function of spectrin and its binding site in UH-RBCs and APH-RBCs.

\section{Methods}

Subjects. Three patients, each with a different unstable hemoglobin variant had routine clinical studies, summarized in Table I. Blood samples from patients and controls were obtained with consent.

1. Abbreviations used in this paper: APH, acetylphenylhydrazine; IOV, inside-out vesicle; ROV, right-side-out vesicle; SS, homozygous sickle cell anemia; UH, unstable hemoglobin. 
Table I. Clinical Studies

\begin{tabular}{lccc}
\hline & Patient 1 & Patient 2 & Patient 3 \\
\hline Unstable hemoglobin & Nottingham & Brockton & Undetermined \\
Hematocrit (\%) & 32 & 30 & 26 \\
Hemoglobin $(\mathrm{g} / \mathrm{dl})$ & 9.4 & 9.7 & 9.0 \\
Reticulocyte $(\%)$ & 17 & 26 & 24
\end{tabular}

Preparation of membranes and membrane proteins. Venous blood was collected in citrate-phosphate-dextrose and stored at $4^{\circ} \mathrm{C}$ for up to $5 \mathrm{~d}$. Abnormal blood samples were stored for up to $48 \mathrm{~h}$. Erythrocyte membranes were prepared by hypotonic hemolysis (24). Isotonic membrane shells were prepared from membranes in a modification of the method of preparing shells from whole cells by incubating them in a buffer of the following composition: Triton X-100 $150 \mathrm{mg} / \mathrm{ml}, \mathrm{NaCl}$ $150 \mathrm{mM}$, Hepes $24 \mathrm{mM}$, EGTA $1 \mathrm{mM}$, phenylmethylsulfonyl fluoride (PMSF) $10 \mu \mathrm{g} / \mathrm{ml}$, leupeptin (Sigma Chemical Co., St. Louis, MO) 10 $\mu \mathrm{g} / \mathrm{ml}$, pepstatin A (Sigma Chemical Co.) $10 \mu \mathrm{g} / \mathrm{ml}, \mathrm{pH} 7.0,5 \mathrm{~min}$, $0^{\circ} \mathrm{C}(25)$. IOVs were separated from low ionic strength extracts by centrifugation, and purified by dextran sedimentation (26). Rightside-out vesicles (ROVs) were produced by resealing erythrocyte membranes as described (27).

Spectrin dimer was extracted from erythrocyte membranes at $37^{\circ} \mathrm{C}$ in $0.1 \mathrm{mM}$ sodium phosphate, $\mathrm{pH} 8$, purified by gel-filtration chromatography (24), and stored at $0^{\circ} \mathrm{C}$ in either IOV-binding buffer $(\mathrm{KCl}$ [130 mM], $\mathrm{NaCl}\left[20 \mathrm{mM}\right.$ ], $\mathrm{NaPO}_{4}$ [10 mM], EDTA [1 mM], $\mathrm{NaN}_{3}$ [0.5 mM], $\mathrm{MgCl}_{2}$ [1 mM], DTT [1 mM], pH 7.5) or buffer of the following composition: $\mathrm{NaCl}(150 \mathrm{mM})$, Tris $(0.01 \mathrm{M})$, EDTA $(0.1$ $\mathrm{mM}), \mathrm{NaN}_{3}(0.02 \%), \mathrm{pH}$ 8.0. Spectrin dimer was used within $5 \mathrm{~d}$ and was shown by nondenaturing polyacrylamide gel electrophoresis (PAGE) (28) to be uncontaminated by tetramer. Spectrin was also extracted from erythrocyte membranes at $0^{\circ} \mathrm{C}$ according to the method of Liu and colleagues (9), and subjected to PAGE under nondenaturing conditions to estimate the degree of spectrin self-association in the native membrane.

Protein 4.1 was extracted from erythrocyte membranes depleted of glyceraldehyde-3-phosphate dehydrogenase (protein 6), spectrin, and actin, using 1\% Tween 20 (Fisher Scientific Co., Springfield, NJ) as described by Liljas and colleagues (29) and modified by Becker and colleagues (30). The extract was chromatographed on a column of DEAE-cellulose (DE-52, Whatman Chemical Separation Inc., Clifton, $\mathrm{NJ})$ equilibrated in a buffer of the following composition: glycine $(0.05$ M), EGTA (0.5 mM), and DTT (0.5 mM), pH 9.8. Purified protein 4.1 was eluted with a continuous gradient of $0-0.5 \mathrm{M} \mathrm{NaCl}$ in the same buffer. Tubes from the upslope of the protein 4.1 peak were uncontaminated with glycophorin. The purified protein was stored at $0^{\circ} \mathrm{C}$, and used within $7 \mathrm{~d}$.

The 72-kD spectrin-binding fragment of ankyrin was released from IOVs by cleavage with $\alpha$-chymotrypsin and purified by DEAE-cellulose chromatography as described by Bennett (31). Rabbit muscle Gactin was prepared and polymerized to F-actin as described by Spudich and Watt (32). Spectrin was radioiodinated with Bolton-Hunter reagent (New England Nuclear, Boston, MA) (33).

Preparation of Heinz Bodies in control erythrocytes. Control erythrocytes were incubated at an hematocrit of $5 \%$, at $37^{\circ} \mathrm{C}$, for $2 \mathrm{~h}$ in a buffer of the following composition: $\mathrm{NaCl}(140 \mathrm{mM}), \mathrm{KCl}(5 \mathrm{mM})$, $\mathrm{MgCl}_{2}$ (1 mM), glycylglycine (20 mM), dextrose (10 mM), bovine serum albumin $(1 \mathrm{mg} / \mathrm{ml})$, penicillin $(100 \mu \mathrm{g} / \mathrm{ml})$, streptomycin $(100$ $\mu \mathrm{g} / \mathrm{ml})$, gentamycin $(15 \mu \mathrm{g} / \mathrm{ml}), \mathrm{pH} 7.4$, with or without $15 \mathrm{mM}$ acetylphenylhydrazine. The cells were then washed either three or six times in 37.5 vol of buffer without APH to remove the APH, and then resuspended to an hematocrit of $5 \%$ and incubated at $37^{\circ} \mathrm{C}$, for up to $48 \mathrm{~h}$ in the same buffer.

Assessment of membrane sidedness. The proportion of IOVs or ROVs that was inside-out was assessed by measuring glyceraldehyde- 3-phosphate dehydrogenase activity (in duplicate) spectrophotometrically before and after the addition of $0.2 \%$ Triton X-100 (27)

Assays of membrane protein interactions. Rebinding of ${ }^{125} \mathrm{I}$-spectrin to spectrin-depleted IOVs was measured as described by Goodman and Weidner (26). Samples of ${ }^{125} \mathrm{I}$-spectrin were heat denatured $\left(70^{\circ} \mathrm{C}\right.$, $10 \mathrm{~min}$ ) and tested at every ${ }^{125} \mathrm{I}$-spectrin concentration in each experiment. Such measurements showed that $5-10 \%$ of the total spectrin was nonspecifically bound. Specific binding was calculated as total binding minus nonspecific binding. All spectrin binding experiments are presented with each point representing the mean of duplicates.

The binding of UH-spectrin (patient 1) and control spectrin to F-actin was assessed in the presence and absence of control protein 4.1 as described by Becker and colleagues (30). Binding of ${ }^{125} \mathrm{I}$-spectrin to F-actin with and without protein 4.1, as a function of total spectrin concentration was measured by sedimentation. The pellets (containing sedimented F-actin and any associated proteins) were analysed by gamma counting for the content of ${ }^{125} \mathrm{I}$-spectrin. Concentrations of

\section{MEMBRANE}
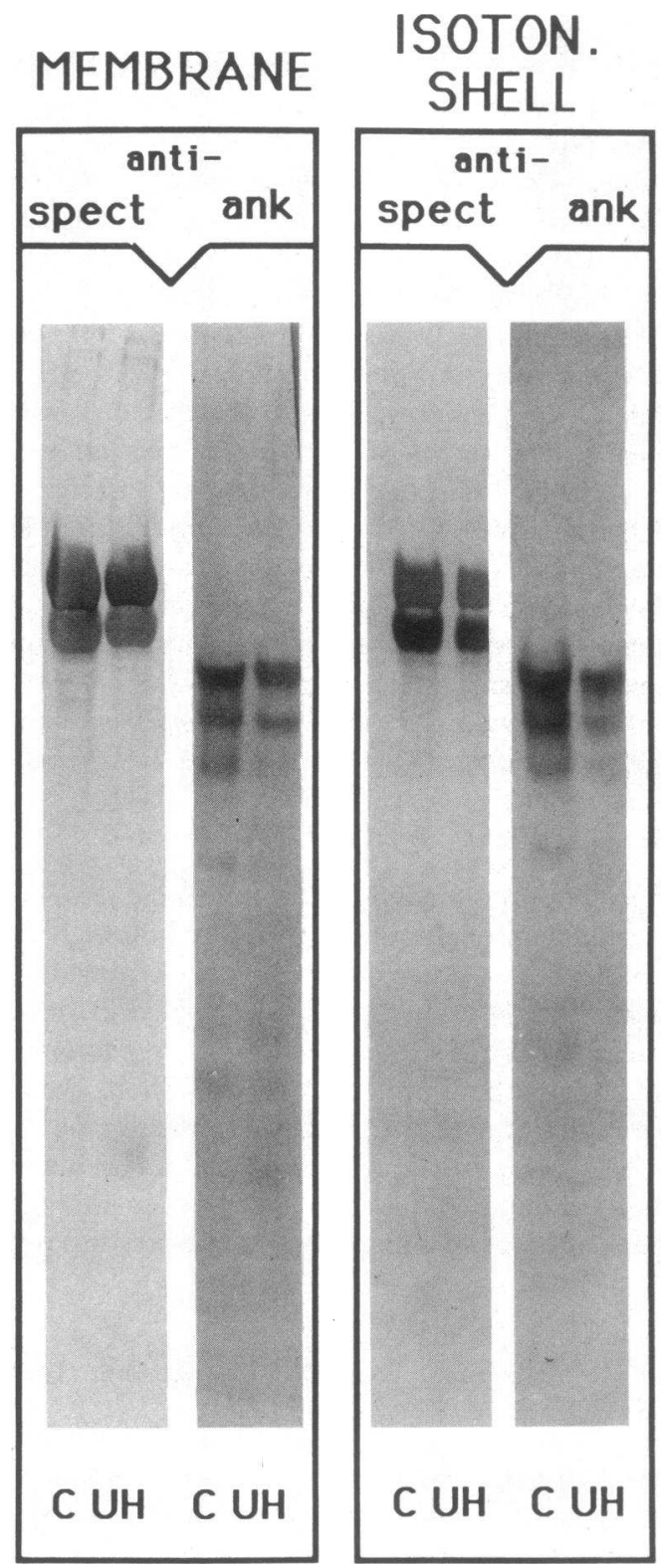

Figure 1. Immunoblots of 3.5-17\% acrylamide gradient Steck gels of control $(C)$ and UH-RBC membranes $(U H)$ and isotonic shells stained with polyclonal rabbit antispectrin (spect) and antiankyrin (ank) antibodies. 
actin and protein 4.1 were in excess, and kept constant in the assay. Nonspecific sedimentation of ${ }^{125} \mathrm{I}$ counts was determined in blanks containing ${ }^{125} \mathrm{I}$-spectrin but no F-actin or protein 4.1, at each spectrin concentration, and was subtracted from the counts in the complete binding mixture. The points on the ${ }^{125} \mathrm{I}$-spectrin-F-actin binding curves represent the mean of duplicates.

Binding of control 72-kD ankyrin fragment, UH-72 kD, and APH-72 kD to control spectrin was determined in a non-denaturing gel system. The ${ }^{125} \mathrm{I} 72-\mathrm{kD}$ fragment was incubated with control spectrin for $60 \mathrm{~min}$ at $0^{\circ} \mathrm{C}$ in conditions described above for the spectrinIOV interaction. The samples were then electrophoresed for 18-24 h at $4^{\circ} \mathrm{C}$ without detergent in a slab gel similar to what was described by Morrow and Marchesi (34) except with an acrylamide gradient of $2-6 \%$.

Other techniques. Protein concentration of membranes and IOVs was estimated according to the method of Lowry et al. (35). Concentrations of purified spectrin, actin, and protein 4.1 were determined spectrophotometrically. Sodium dodecyl sulfate (SDS)-PAGE was performed by the methods of Steck (36), Fairbanks et al. (37), and Laemmli (38). Nondenaturing PAGE of purified spectrin was done using a modification of the Steck method (36), omitting SDS, and using 3\% acrylamide. The amounts of spectrin, ankyrin, protein 3, actin, or globin in erythrocyte membranes IOVs, or shells, were quantitated by cutting out bands 1, 2, 2.1, 3, or 5 from Coomassie Brilliant Blue-stained SDS-PAGE slabs, eluting the dye overnight in $1 \mathrm{ml}$ pyridine (25\%), and reading the optical density of the eluate at $605 \mathrm{~nm}$ (39). Blot transfer of gel proteins to nitrocellulose was performed in a water-cooled system in $25 \mathrm{mM}$ Tris, $192 \mathrm{mM}$ glycine, 20\% (vol/vol) methanol, at $350 \mathrm{~mA}$ for $3 \mathrm{~h}$. The transferred proteins were stained with amido black and/or were blocked and immunostained (Protoblot, Promega, Madison, WI) after having been exposed to rabbit antibodies to spectrin, ankyrin, or protein 4.1 .

\section{Results}

Composition of membranes, vesicles, shells, and protein preparations. Comparison of SDS-PAGE of control and UH-RBC membranes reveals increased globin and catalase (as seen in many other hemolytic anemias) (40) and decreased spectrin (previously seen only in the various forms of hereditary spherocytosis and pyropoikilocytosis variants) $(41-44)$ in the UHRBC membranes. Quantitation of spectrin by pyridine elution revealed that control erythrocytes (two individuals with three and five determinations, respectively) had a spectrin/protein 3 ratio of $0.92 \pm 0.08$. UH-RBC membranes (patients 1,2 , and 3, each with five determinations) had a spectrin/protein 3 ratio of $0.61 \pm 0.14$. The ratio of spectrin to globin in whole cell preparations was $0.32 \pm 0.04$ in control and $0.22 \pm 0.02$ in patient 2 . Neither whole cells, nor isotonic shells of either control or UH-RBCs revealed spectrin degradation products by nitrocellulose transfer and immuno staining with rabbit antispectrin antibody (Fig. 1).

Ankyrin quantitation showed no difference between control (ankyrin/protein 3 ratio $0.186 \pm 0.055$ ) and UH-IOVs $(0.168 \pm 0.053)$, but a decrease in the amount of ankyrin in UH-shells. Control shells had an ankyrin/actin ratio of $1.86 \pm 0.51$ with a ratio of $0.19 \pm 0.07$ in the UH-shells (patient 2). Immunostaining of protein transfers from control and UH-shells revealed no significant proteolysis of the UH-ankyrin when probed with antiankyrin antibody (Fig. 1).

In control IOVs, hemoglobin/protein 3 ratios were $0.016 \pm 0.003$; the hemoglobin/protein 3 ratio of the UH-IOVs was $0.4 \pm 0.07$. Both control and UH-IOV preparations were comparably inside-out. The accessibility of glyceraldehyde-3phosphate dehydrogenase was $92 \% \pm 2.8 \%$ in control IOVs, and $88.5 \% \pm 4.9 \%$ in UH-IOVs. In ROVs, glyceraldehyde-3-phosphate dehydrogenase accessibility was $30 \%$.

Control spectrin and $\mathrm{UH}$-spectrin extracted at low ionic strength and $0^{\circ} \mathrm{C}$ did not differ in the relative amounts of dimer and tetramer, suggesting the same relative degree of spectrin self-association in the native membranes. However, a faint slightly faster-running band just below the dimer band is
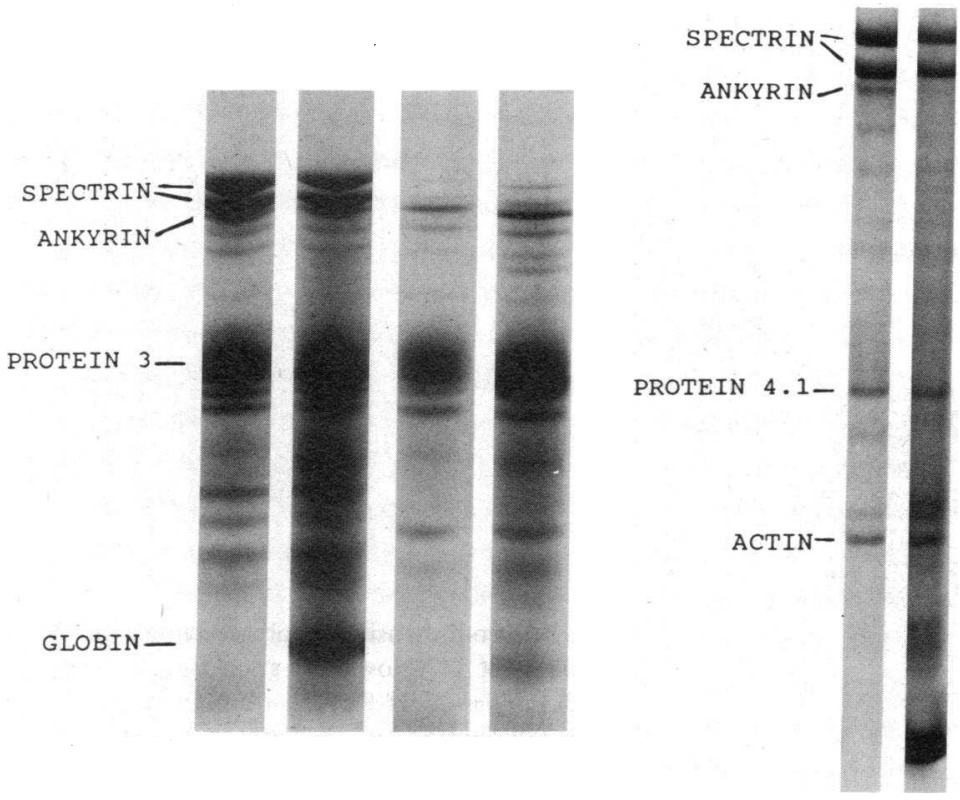

A
D
Figure 2. PAGE of $(A)$ control RBC membranes, $(B)$ UH-RBC membranes, $(C)$ control IOVs, $(D)$ UH-IOVs, $(E)$ control isotonic RBC membrane shells, $(F)$ UH-isotonic shells, $(G)$ control spectrin, $4^{\circ} \mathrm{C}$ extract, $(H) \mathrm{UH}$-spectrin, $4^{\circ} \mathrm{C}$ extract, $(I)$ control spectrin, $37^{\circ} \mathrm{C}$

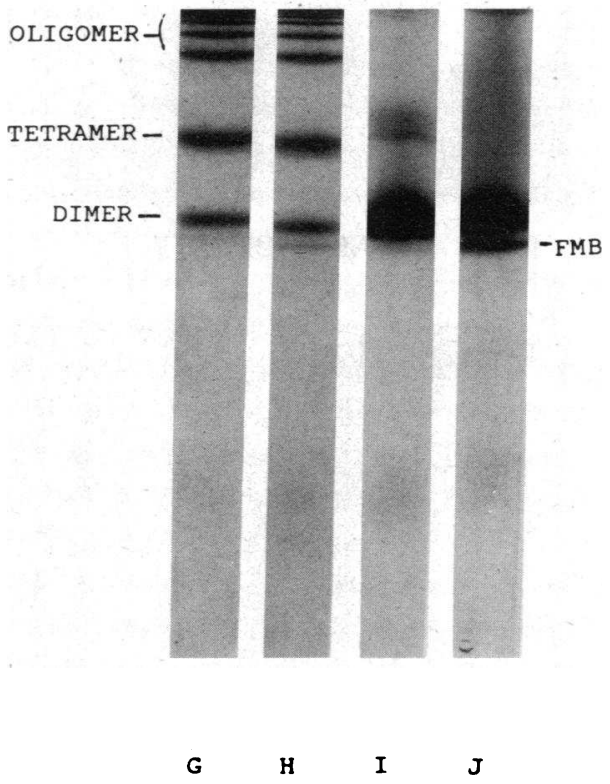

extract, $(J)$ UH-spectrin, $37^{\circ} \mathrm{C}$ extract. Lanes $A-D$ are SDS-PAGE of $40 \mu \mathrm{g}$ of protein by the method of Steck and Kant (27). Lanes $E$ and $F$ are 3.5-17\% acrylamide gradient Steck gels. Lanes $I-L$ are nondenaturing $3 \%$ acrylamide gels of $20 \mu$ g protein. 
apparent in the unstable hemoglobin preparation (Fig. 2). In nondenaturing PAGE of control spectrin and UH-spectrin extracted at $37^{\circ} \mathrm{C}$, the same predominance of dimer is seen in both preparations, but the faster-running band is seen in the UH-spectrin extracts, but not in the controls. This band was not abolished by treatment with $100 \mathrm{mM}$ DTT at $\mathrm{pH} 8,0^{\circ} \mathrm{C}$ overnight, and did resolve only into bands 1 and 2 when run in the second dimension with SDS (Fig. 3).

Spectrin binding sites of $U H-R B C s$ and $A P H-R B C s$ are abnormal. Membrane binding sites for spectrin were examined in situ by comparison of the capacities of control and UHIOVs to bind normal ${ }^{125} \mathrm{I}$-spectrin. The results in Fig. 4 indicate that UH-IOVs (patients 1, 2, and 3) bind much less spectrin than do control IOVs. Identical results were obtained when UH-IOVs were prepared from freshly drawn UH-RBCs or UH-RBCs stored for up to $48 \mathrm{~h}$.

As seen in Fig. 5, the spectrin binding capacity of APHIOVs prepared from erythrocytes that were exposed to $15 \mathrm{mM}$ APH for $2 \mathrm{~h}$ (conditions which produced numerous large Heinz bodies) and then washed free of APH, was normal. In contrast, APH-IOVs from erythrocytes incubated with APH under the same conditions, washed free of APH (either three or six times in $37.5 \mathrm{vol}$ of buffer without APH), but then allowed to incubate without APH for $48 \mathrm{~h}$, had markedly diminished spectrin binding. During the incubation, more hemoglobin became associated with both the control and APHIOVs. After the initial 2-h incubation without APH, control IOVs had a hemoglobin/protein 3 ratio of $0.03 \pm 0.01$. This ratio increased to $0.1 \pm 0.01$ after the 48 -h incubation. After the initial incubation with APH, APH-IOVs had a high hemoglobin/protein 3 ratio of $0.17 \pm 0.02$. After further incubation of these cells for $48 \mathrm{~h}$ without APH, considerably more hemoglobin became associated with the APH-IOVs, with a hemoglobin/protein 3 ratio of $1.2 \pm 0.08$.

The binding of control 72-kD, UH-72-kD, and APH-72$\mathrm{kD}$ ankyrin fragments to spectrin is shown in Fig. 6. The left side of the figure represents denisitometry tracings from the autoradiograph of the same slab. The top panel shows the mobility of ${ }^{125} \mathrm{I}$-control $72-\mathrm{kD}$ fragment alone and is indicated by the arrow. In the panel below it, unlabeled spectrin was added, and the position of the spectrin-72- $\mathrm{kD}$ complex is indicated by the arrow. Note that both bound and unbound

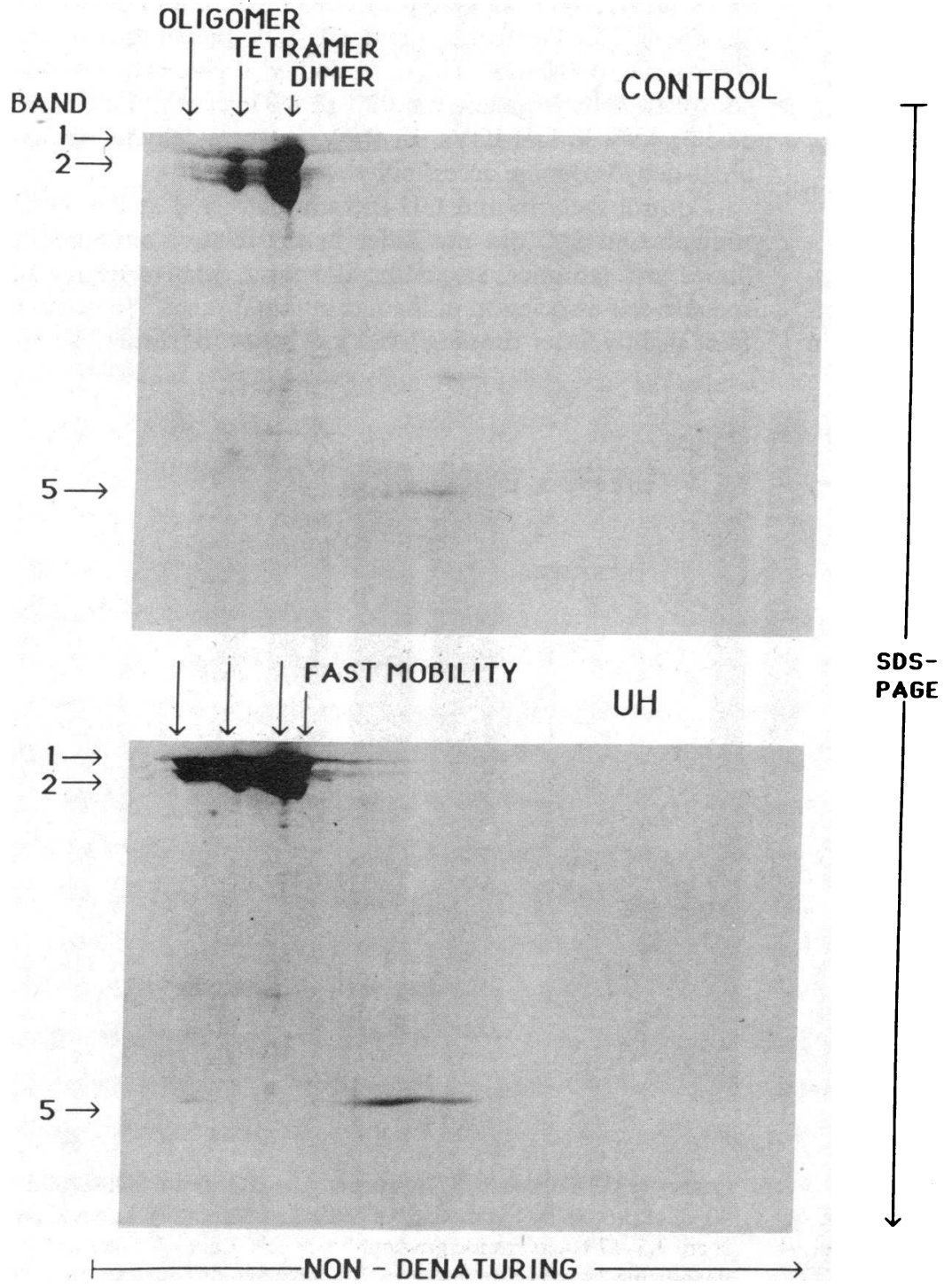

Figure 3. Two-dimensional polyacrylamide gel electrophoresis of $37^{\circ} \mathrm{C}$ low ionic strength extracts from control (top) and UH-RBC (bottom) membranes. The first dimension is a $3 \%$ acrylamide Steck gel without SDS. The second dimension is a Laemmli slab. The second dimension gel is loaded heavily to enhance the appearance of protein components. Only bands 1 and 2 of spectrin are seen in the oligomer, tetramer, dimer, and fast mobility bands. Actin (band 5), not visible in the original first dimension (Fig. 2) is seen in the second dimension. 


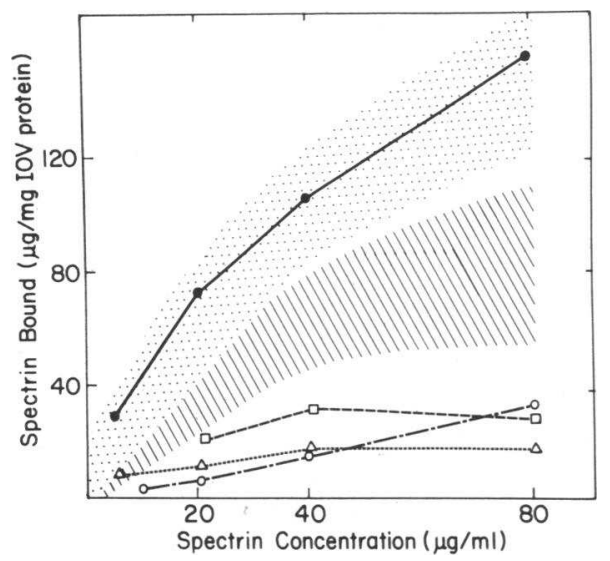

Figure 4. The binding of control spectrin dimer to UH-IOVs from patients $1(\square), 2(\Delta)$, and $3(0)$, and control $(\bullet)$ IOVs. Various concentrations of ${ }^{125} \mathrm{I}$-spectrin dimer were incubated for $90 \mathrm{~min}$ at $0^{\circ} \mathrm{C}$ in a $0.225-\mathrm{ml}$ volume containing $\mathrm{KCl}(130 \mathrm{mM}), \mathrm{MgCl}_{2}(1 \mathrm{mM})$, $\mathrm{NaCl}(20 \mathrm{mM})$, EDTA (1 mM), $\mathrm{NaN}_{3}(0.5 \mathrm{mM})$, DTT (1.0 mM), $\mathrm{NaPO}_{4}(10 \mathrm{mM}), \mathrm{pH} 7.5$, and $16.65 \mu \mathrm{g}$ of IOV protein. Membranebound and free radioactivity were separated by pelleting of the membrane-bound ${ }^{125}$ I-spectrin dimer through a $20 \%$ sucrose cushion and were determined in duplicate for each point. The binding is corrected for nonspecific components by subtraction of the values for heat-denatured ${ }^{125} \mathrm{I}$-spectrin. The points are presented as the mean of the duplicates. The shaded areas represent the range of binding curves previously determined for control and SS-IOVs (10).

$72-\mathrm{kD}$ material is present. The position of ${ }^{125} \mathrm{I}-\mathrm{UH}-72-\mathrm{kD}$ alone is shown in the third panel on the left. Most of the material runs in the same position as the normal 72-kD material, however, a fast-running band, indicated by the arrow is also seen. When spectrin is added in the same ratio to this 72-kD preparation, the complex runs in the normal position, and the 72-kD peak in the normal position is diminished, but the fast-running $72-\mathrm{kD}$ peak appears to remain unbound to the spectrin. A similar finding is apparent in the experiment using APH-72-kD as illustrated in the tracings on the right. The positions of the control ${ }^{125} \mathrm{I}-72-\mathrm{kD}$ and the $72-\mathrm{kD}-\mathrm{spec}-$

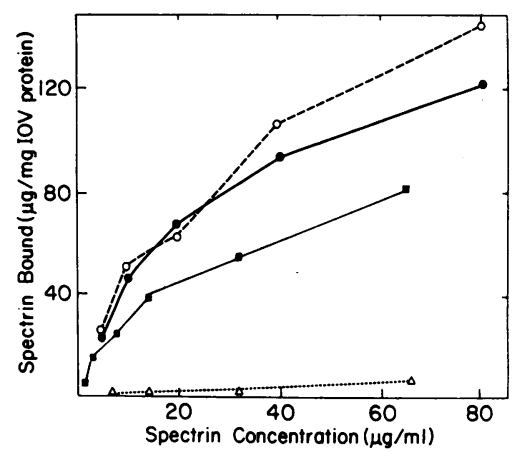

Figure 5. The binding of control spectrin dimer to IOVs prepared from control erythrocytes which had incubated under various conditions. ( $(0)$ Incubated at an Hct of $5 \%$, at $37^{\circ} \mathrm{C}$, for $2 \mathrm{~h}$ in the following buffer: $\mathrm{NaCl}$ (140 mM), $\mathrm{KCl}(5$ $\mathrm{mM}), \mathrm{MgCl}_{2}(1 \mathrm{mM})$, glycylglycine (20 mM), dextrose $(10 \mathrm{mM})$, bovine serum albumin $(1 \mathrm{mg} / \mathrm{ml})$, penicillin $(100$ $\mu \mathrm{g} / \mathrm{ml})$, streptomycin $(100 \mu \mathrm{g} / \mathrm{ml})$, gentamycin $(15 \mu \mathrm{g} / \mathrm{ml})$, APH (15 $\mathrm{mM})$, pH 7.4. The cells were then washed to remove the APH. (•) Incubated under the conditions described above, except without APH. ( $\triangle$ ) Incubated under the conditions described above, washed free of APH, then incubated for $48 \mathrm{~h}$ in the same buffer, without APH. (घ) Incubated under the conditions described above except without APH in either the 2- or 48-h incubations. Various concentrations of ${ }^{125} \mathrm{I}$-spectrin were incubated with the above IOVs as described in Fig. 4.

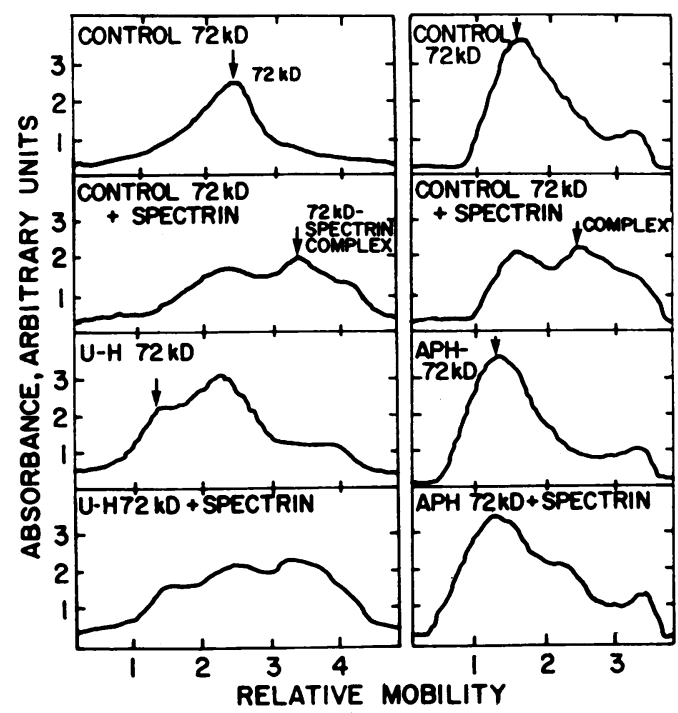

Figure 6. Binding of control ${ }^{125} \mathrm{I}-72-\mathrm{kD},{ }^{125} \mathrm{I}-\mathrm{UH}-72-\mathrm{kD}$, and ${ }^{125} \mathrm{I}-$ APH-72-kD ankyrin fragments to normal spectrin. Each ${ }^{125} \mathrm{I}-72-\mathrm{kD}$ species was incubated either alone or with spectrin for $60 \mathrm{~min}$ at $0^{\circ} \mathrm{C}$ in the buffer described in Fig. 3. 20,000 cpm of each incubation mixture was loaded onto a nondenaturing slab gel with an acrylamide gradient of $2-6 \%$. The gel was electrophoresed at $50 \mathrm{~V}$ for $18-24 \mathrm{~h}$ at $4^{\circ} \mathrm{C}$. Autoradiography was then performed, and the $\mathrm{x}$-ray was subjected to laser densitometric scanning. The tracings in the panel on the left represent the results of scanning the slab gel containing a control and UH-72-kD experiment. On the right is the result of scanning another gel with control and APH-72-kD experiments. The top tracings illustrate the positions of the control $72-\mathrm{kD}$ fragments, indicated by arrows. The second tracings illustrate the positions of unbound 72-kD fragments, and the spectrin-72-kD complex (indicated by the arrows). The third tracings show the abnormal mobility of the UH-72-kD fragment which has a fast-running component (indicated by the arrow) and the APH-72-kD fragment which is uniformly faster running (indicated by the arrow). In the bottom tracings, the normal position of the 72-kD-spectrin complex is seen along with an increase in unbound $72-\mathrm{kD}$ fragments.

trin complex are indicated by arrows in the top two panels. The position of the ${ }^{125} \mathrm{I}-\mathrm{APH}-72-\mathrm{kD}$ alone is indicated by the arrow in the third panel, and is faster than the control 72-kD. When spectrin is added to the APH-72-kD as shown in the bottom panel, very little complex is formed.

Despite the altered mobility of the UH-72-kD and APH-72-kD fragments in this non-denaturing system, both preparations ran in identical position in denaturing gels. As seen in Fig. 7, the fast-moving material seen in the nondenaturing dimension is of the same apparent molecular weight, and reacts with antiankyrin antibody as does the control material.

The ankyrin binding site of UH-spectrin is normal. The ankyrin-binding site of UH-spectrin is examined by comparison of the binding of ${ }^{125} \mathrm{I}-\mathrm{UH}$-spectrin and control ${ }^{125} \mathrm{I}$-spectrin to control IOVs. No difference in binding is observed (Fig. 8), indicating that the ankyrin binding site of UH-spectrin (patient 1 ) is normal.

The binding of UH-spectrin to F-actin in the presence of protein 4.1 is reduced. The enhancement of binding of spectrin to actin by protein 4.1 was studied by comparing $\mathrm{UH}$-spectrin (patient 1 ) and control spectrin binding to F-actin in the presence and absence of protein 4.1. As seen in Fig. 9, both spec- 


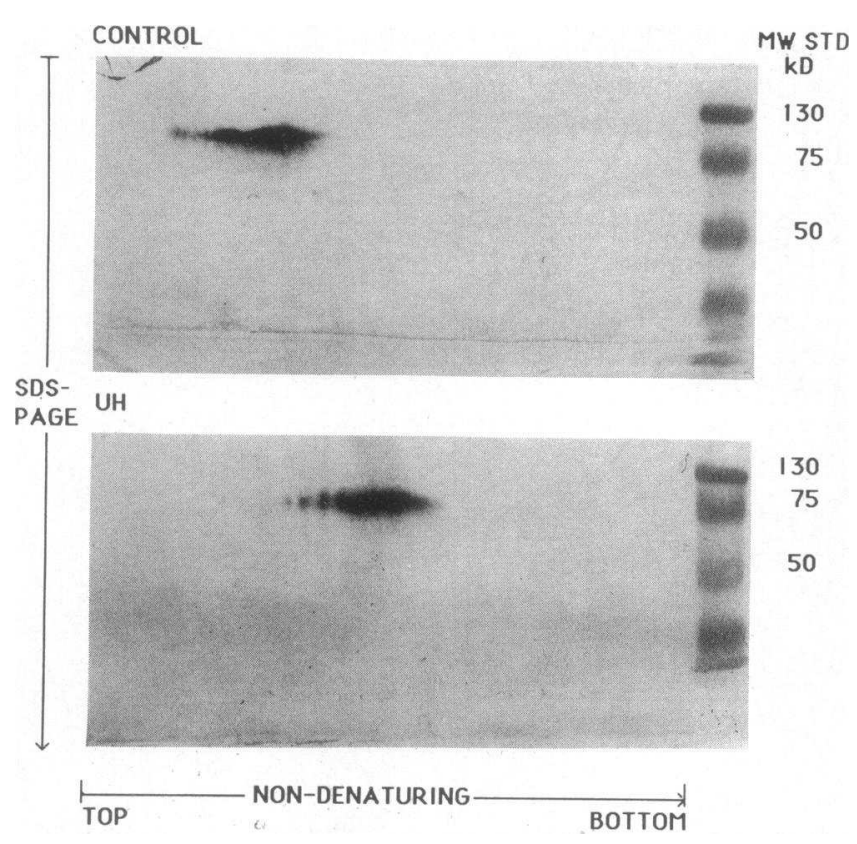

Figure 7. 72-kD ankyrin fragment from control (top) and UH-RBC (bottom) membranes. The fragments were run in parallel lanes in a $3 \%$ nondenaturing Laemmli slab gel. The lanes were then cut, aligned identically with the bottom of the lanes abutting a single lane containing prestained molecular weight standards (MW STD) and run in the second dimension in a $4 \%$ acrylamide Steck slab gel with SDS. The electrophoresed proteins were transferred to nitrocellulose paper, and immunostained with a polyclonal rabbit antiankyrin antibody.

trins bind comparably to $\mathrm{F}$-actin in the absence of protein 4.1. However, in the presence of protein 4.1, UH-spectrin does not bind F-actin as well as control.

\section{Discussion}

We examined protein composition and function in UH-RBC membranes, and found three major abnormalities: $(a)$ decreased binding of control spectrin to UH-IOVs, as seen in SS-IOVs (10), (b) alteration of UH-spectrin structure and function, as seen with artifieially oxidized spectrin (45), and (c) decreased spectrin content, as seen in hereditary spherocytosis of mice (46), and men $(41,42,44)$.

Decreased binding of spectrin to UH-IOVs. The diminished capacity of UH-IOVs to bind to normal spectrin is even more profound than what we observed with SS-IOVs (Fig. 4), or what has been observed in one family with hereditary elliptocytosis (47). As we have previously shown (10), this decreased

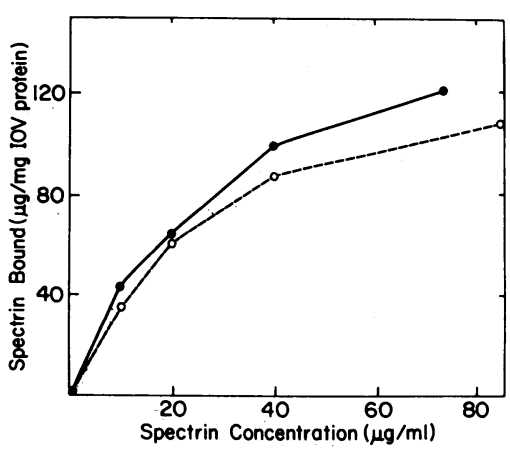

Figure 8. The binding of control (๑) and UHspectrin (o) dimer to control IOVs. Various concentrations of the ${ }^{125}$ I-spectrin dimers were incubated with control IOVs as described in Fig. 4.

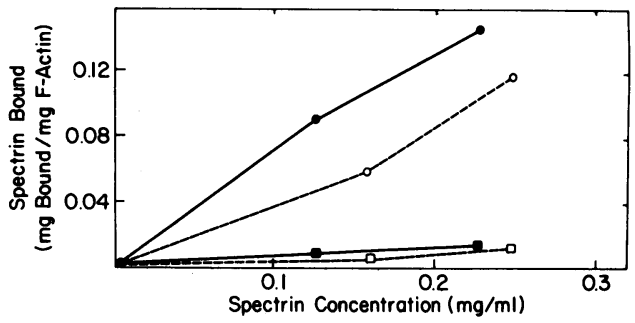

Figure 9. The binding of control spectrin (๑) and UH-spectrin (O) dimer to F-actin in the presence $(\bullet, 0)$ and absence $(\bullet, \square)$ of protein 4.1. Various concentrations of ${ }^{125} \mathrm{I}$-spectrin dimer were incubated in a volume of $80 \mu \mathrm{l}$ at room temperature for $90 \mathrm{~min}$ in the following buffer: $\mathrm{NaCl}(150 \mathrm{mM}), \mathrm{KCl}(5 \mathrm{mM}), \mathrm{MgCl}_{2}(0.5 \mathrm{mM}), \mathrm{CaCl}_{2}(0.01$ $\mathrm{mM}), \mathrm{NaPO}_{4}(4 \mathrm{mM})$, Tris $(10 \mathrm{mM})$, EDTA $(0.037 \mathrm{mM})$, ATP $(0.1$ $\mathrm{mM})$, DTT $(0.5 \mathrm{mM}), \mathrm{pH} 8.0$ with $21 \mu \mathrm{g}$ of F-actin, with or without $6 \mu \mathrm{g}$ of protein 4.1. F-actin bound and free radioactivity were separated by pelleting the F-actin-bound ${ }^{125} \mathrm{I}$-spectrin dimer through a $5 \%$ sucrose cushion and were determined in duplicate for each point. The binding was corrected for nonspecific sedimentation of ${ }^{\mathrm{I} 25} \mathrm{I}$-spectrin counts in blanks containing the various amounts of spectrin, but no protein 4.1 or F-actin.

binding is not an artifact of reticulocytosis, nor as suggested by the UH-IOV sidedness assays, is it a case of faulty IOV production. We present two lines of evidence which suggest that UHankyrin is altered. The isolated UH-72-kD ankyrin fragment has a slightly different electrophoretic pattern in nondenaturing gels, and appears to bind less well than control $72-\mathrm{kD}$ ankyrin fragment to spectrin. In addition, isotonic UH-shells contain $10 \%$ of the amount of ankyrin found in control shells, a testimony to the faulty interaction between UH-ankyrin and spectrin. Although we infer from these experiments that ankyrin is damaged in UH-RBCs, it remains to be seen what the relative contributions are of steric hindrance, altered phosphorylation pattern, and/or direct oxidative damage of ankyrin by bound hemoglobin products, and the altered distribution of protein 3 .

In an attempt to examine the role of oxidation in the creation of the UH-IOV spectrin binding lesion, we exposed normal erythrocytes to APH. The various hydrazines interact with oxyhemoglobin in intact erythrocytes, and in a matter of minutes generate superoxide, $\mathrm{H}_{2} \mathrm{O}_{2}$, and Heinz bodies $(21,22)$. We were surprised to find that after incubating in APH for $2 \mathrm{~h}$, although virtually every erythrocyte was laden with Heinz bodies, APH-IOVs bound spectrin normally (Fig. 5). It was only when such Heinz body-containing APH-RBC were allowed to incubate under physiological conditions (in the absence of APH) for $48 \mathrm{~h}$ that the APH-IOV spectrin-binding lesion ecame apparent (Fig. 5). This experiment suggests that the initial surge of oxidants which results from the reaction of APH with oxy-hemoglobin is not immediately sufficient to generate the binding impairment. The additional time requirement allows more denatured hemoglobin to bind to the membrane and more localized oxidants to be generated in the immediate vicinity of the membrane proteins. In this model, the APH oxidant storm creates the Heinz bodies, and the Heinz bodies create the APH-IOV binding lesion. The APH-72-kD ankyrin fragment demonstrates both altered mobility in nondenaturing gels and decreased binding to normal spectrin, as seen in UH-72-kD.

Abnormal structure and function of $U H$-spectrin. We purified spectrin from UH-RBCs and studied several of its properties: ability to bind to normal IOVs, ability to self-associate in 
the membrane and disassociate at low ionic strength at $37^{\circ} \mathrm{C}$, ability to bind to F-actin, and ability to exhibit enhanced binding to F-actin in the presence of protein 4.1. We found that UH-spectrin bound normally to normal IOVs (Fig. 8), and bound normally to F-actin in the absence of protein 4.1 (Fig. 9). However, in the presence of protein 4.1, UH-spectrin binding to F-actin was not enhanced to the same degree as control (Fig. 9). The relative degree of spectrin self-association in the membrane was normal, as was the tendency for the spectrin to dissociate into dimers at $37^{\circ} \mathrm{C}$ in low ionic strength (Fig. 1). However, a faint band of spectrin, running slightly faster than spectrin dimer, was seen on nondenaturing PAGE in the UHspectrin preparations (both at $0^{\circ} \mathrm{C}$ and at $37^{\circ} \mathrm{C}$ ) but not in the controls (Fig. 1). This band was most pronounced in conditions favoring dimer formation, and appeared in the purified dimer peak eluted off a gel-filtration column. A band of this mobility and composition was described as "fast mobility band" by Becker and her colleagues (45), and was produced by treating normal spectrin with the oxidizing agent, diamide (diamide-spectrin).

In fact, the resemblance between UH-spectrin and diamide-spectrin is not only in the appearance of the fast mobility band, but in the entire pattern of spectrin function. Both UH- and diamide-spectrins bind normally to IOVs, convert readily to dimer or tetramer under appropriate conditions, bind normally to F-actin in the absence of protein 4.1, and fail to exhibit enhanced binding to F-actin in the presence of protein 4.1. However, there are subtle differences between these two species of spectrin: the fast mobility band of UH- and diamide-spectrins are similarly dysfunctional, but the UHspectrin lesions are less readily reversible than the diamideinduced spectrin lesions.

Decreased spectrin content in UH-RBC membranes. We quantitated the amount of spectrin in UH-RBC membranes and found it to be markedly reduced. Reduction in spectrin content had been previously documented only in hereditary spherocytosis and pyropoikilocytosis erythrocytes (41-44). Although the osmotic fragility profiles of UH-RBCs do not reveal a population of osmotically fragile cells, there are between 5 and $10 \%$ spherocytes identifiable on peripheral smears. The mechanism of the spectrin deficiency is unknown even in hereditary spherocytosis. Here it is possible that UH-RBCs acquire an oxidative lesion of spectrin that allows them to behave functionally like the rare (spectrin-deficient) hereditary spherocytosis patients with genetically impaired spectrin which has lost the ability to bind normally to F-actin in the presence of protein $4.1(48,49)$.

In summary, we find two classes of membrane protein lesions in UH-RBCs, a lesion(s) of the UH-IOV, and a lesion(s) of UH-spectrin itself. The UH-IOV lesion is a functional defect of the spectrin binding site of ankyrin which is more profound than what we demonstrated in SS-IOVs. The UH-spectrin lesion involves spectrin deficiency as well as a pattern of normal and abnormal functions which resembles the pattern of diamide-spectrin. This suggests that damage to UH-RBC membranes may be a gradual process that results from globin deposition and oxidation in vivo.

\section{Acknowledgments}

The authors thank Drs. S. E. Lux and V. Ohanian for their helpful discussions and advice.

This study was supported by grant HL-15151 from the National
Heart, Lung and Blood Institute and a grant from the National Association for Sickle Cell Disease, Inc.

\section{References}

1. Shaklai, N., J. Yguerabide, and H. M. Ranney. 1977. Interaction of hemoglobin with red blood cell membranes as shown by a fluorescent chromophore. Biochemistry. 16:5585-5592.

2. Shaklai, N., J. Ygurabide, and H. M. Ranney. 1977. Classification and localization of hemoglobin binding sites on the red blood cell membrane. Biochemistry. 16:5593-5597.

3. Premachandra, B. R. 1986. Interaction of hemoglobin and its component alpha and beta chains with band 3 protein. Biochemistry. 25:3455-3462.

4. Salhany, J. M., K. A. Cordes, and E. D. Gains. 1980. Light-scattering measurements of hemoglobin binding to the erythrocyte membrane. Evidence for transmembrane effects related to a disulfonic stilbene binding to band 3. Biochemistry. 19:1447-1454.

5. Sayare, M., and M. Fikiet. 1981. Cross-linking of hemoglobin to the cytoplasmic surface of human erythrocyte membranes. J. Biol. Chem. 256:13152-13158.

6. Eisinger, J., J. Flores, and J. M. Salhany. 1982. Association of cytosol hemoglobin with the membrane in intact erythrocytes. Proc. Natl. Acad. Sci. USA. 79:408-412.

7. Cassoly, R. 1983. Quantitative analysis of the association of human hemoglobin with the cytoplasmic fragment of band 3 protein. J. Biol. Chem. 258:3859-3864.

8. Walder, J. A., R. Chaterjee, T. L. Steck, P. S. Low, G. F. Musso, E. T. Kaiser, P. H. Rogers, and A. Arnone. 1984. The interaction of hemoglobin with the cytoplasmic domain of band 3 of the human erythrocyte membrane. J. Biol. Chem. 259:10238-10246.

9. Liu, S.-C., and J. Palek. 1984. Hemoglobin enhances the self-association of spectrin heterodimers in human erythrocytes. J. Biol. Chem. 259:11556-11562.

10. Platt, O. S., J. F. Falcone, and S. E. Lux. 1985. Molecular defect in the sickle erythrocyte skeleton, abnormal spectrin binding to sickle inside-out vesicles. J. Clin. Invest. 75:266-271.

11. Shaklai, N., V. S. Sharma, and H. M. Ranney. 1981. Interaction of sickle cell hemoglobin with erythrocyte membranes. Proc. Natl. Acad. Sci. USA. 78:65-68.

12. Waugh, S. M., and P. S. Low. 1985 . Hemichrome binding to band 3: nucleation of Heinz Bodies on the erythrocyte membrane. Biochemistry. 24:34-39.

13. Low, P. S., S. M. Waugh, K. Zinke, and D. Drenckhahn. 1985. The role of hemoglobin denaturation and band 3 clustering in red blood cell aging. Science (Wash. DC). 227:531-533.

14. Waugh, S. M., J. A. Walder, and P. S. Low. 1987. Partial characterization of the copolymerization reaction of erythrocyte membrane band 3 with hemichromes. Biochemistry. 26:1777-1783.

15. Schluter, K. and D. Drehckhahn. 1986. Co-clustering of denatured hemoglobin with band 3: its role in binding of autoantibodies against band 3 to abnormal and aged erythrocytes. Proc. Natl. Acad. Sci. USA. 83:6137-6141.

16. Waugh, S. M., B. M. Willardson, R. Kannan, R. J. Labotka, and P. S. Low. 1986. Heinz bodies induce clustering of band 3, glycophorin, and ankyrin in sickle cell erythrocytes. J. Clin. Invest. 78:1155-1160.

17. Hebbel, R. P., and W. J. Miller. 1984. Phagocytosis of sickle erythrocytes: immunologic and oxidative determinants of hemolytic anemia. Blood. 64:73.

18. Hebbel, R. P., J. W. Eaton, M. Balasingam, and M. H. Steinberg. 1982. Spontaneous generation of oxygen radical generation by sickle erythrocytes. J. Clin. Invest. 70:1253-1259.

19. Rank, B. H., J. Carlsson, and R. P. Hebbel. 1985. Abnormal redox status of membrane-protein thiols in sickle erythrocytes. J. Clin. Invest. 75:1531-1537.

20. Flynn, T. P., D. W. Allen, G. J. Johnson, and J. G. White. 1983. Oxidant damage of the lipids and proteins of the erythrocyte membranes in unstable hemoglobin disease. J. Clin. Invest. 71:1215-1223. 
21. Jain, S. K., and P. Hochstein. 1979. Generation of superoxide radicals by hydrazine. Its role in phenylhydrazine-induced hemolytic anemia. Biochim. Biophys. Acta. 586:128-136.

22. Jain, S. K., and P. Hochstein. 1980. Polymerization of membrane components in aging red blood cells. Biochem. Biophys. Res. Commun. 92:247-254.

23. Rice-Evans, C. and P. Hochstein. 1981. Alterations in erythrocyte membrane fluidity by phenylhydrazine-induced peroxidation of lipids. Biochem. Biophys. Res. Commun. 100:1537-1542.

24. Lux, S. E., K. M. John, and T. E. Ukena. 1978. Diminished spectrin extraction from ATP-depleted human erythrocytes: evidence relating spectrin to changes in erythrocyte shape and deformability. $J$. Clin. Invest. 61:815-827.

25. Ohanian, V., and W. Gratzer. 1984. Preparation of red-cellmembrane cytoskeletal constituents and characterisation of protein 4.1. Eur. J. Biochem. 144:375-379.

26. Goodman, S. R., and S. A. Weidner. 1980. Binding of spectrin a2-b2 tetramers to human erythrocyte membranes. J. Biol. Chem. 255:8082-8086.

27. Steck, T. L., and J. A. Kant. 1974. Preparation of impermeable ghosts and inside-out vesicles from human erythrocyte membranes. Methods Enzymol. 31:172-179.

28. Liu, S.-C., J. Palek, J. Prcal, and R. Castleberry. 1981. Altered spectrin dimer-dimer association and instability of erythrocyte membrane skeletons in hereditary pyropoikilocytosis. J. Clin. Invest. 68:597-605.

29. Liljas, L., Lundahl, P., and S. Hjerten. 1974. Selective solubilization with Tween 20 of proteins from water-extracted human erythrocyte membranes. Analysis by gel electrophoresis in dodecyl sulfate and in Tween 20. Biochim. Biophys. Acta. 352:327-337.

30. Becker, P. S., J. E. Spiegel, L. C. Wolfe, and S. E. Lux. 1983. High yield purification of protein 4.1 from human erythrocyte membranes. Anal. Biochem. 132:195-201.

31. Bennett, V. 1978. Purification of an active proteolytic fragment of the membrane attachment site for human erythrocyte spectrin. $J$. Biol. Chem. 253:2292-2299.

32. Spudich, J. A., and S. J. Watt. 1971. The regulation of rabbit skeletal muscle contraction. I. Biochemical studies of the interaction of the tropomyosin-troponin complex with actin and the proteolytic fragments of myosin. J. Biol. Chem. 99:886-893.

33. Tyler, J. M., B. N. Reinhardt, and D. Branton. 1980. Associations of erythrocyte membrane proteins: binding of purified bands 2.1 and 4.1 to spectrin. J. Biol. Chem. 255:7034-7039.

34. Morrow, J. S., and V. T. Marchesi. 1981. Self-assembly of spectrin oligomers in vitro: a basis for a dynamic cytoskeleton. J. Cell Biol. 88:463-468.
35. Lowry, O. H., N. J. Rosebrough, A. L. Farr, and R. J. Randall. 1951. Protein measurement with the Folin reagent. J. Biol. Chem. 193:265-275.

36. Steck, T. L. 1972. Cross-linking the major proteins of the isolated erythrocyte membrane. J. Mol. Biol. 66:295-305.

37. Fairbanks G., T. L. Steck, and D. F. H. Wallace. 1971. Electrophoretic analysis of the major polypeptides of the human erythrocyte membrane. Biochemistry. 10:2606-2617.

38. Laemmli, U. K. 1970. Cleavage of structural proteins during the assembly of bacteriophage T4. Nature (Lond.) 227:680-685.

39. Fenner, C., R. R. Traut, D. T. Mason, and J. Wikman-Coffelt. 1975. Quantification of Coomassie blue stained proteins in polyacrylamide gels based on analysis of eluted dye. Anal. Biochem. 63:603606.

40. Allen, D. W., S. Cadman, S. R. McCann, and B. Finkel. 1977. Increased membrane binding of erythrocyte catalase in hereditary spherocytosis and in metabolically stressed normal cells. Blood. 49:113-123.

41. Agre, P., E. P. Orringer, and V. Bennett. 1982. Deficient redcell spectrin in severe, recessively inherited spherocytosis. $N$. Engl. $J$. Med. 306:1155-1161.

42. Agre, P., J. F. Casella, W. H. Zinkham, C. McMillan, and V. Bennett. 1985. Partial deficiency of erythrocyte spectrin in hereditary spherocytosis. Nature (Lond.) 314:380-383.

43. Coetzer, T. L., and J. Palek. 1986. Partial spectrin deficiency in hereditary pyropoikilocytosis. Blood. 67:919-924.

44. Agre, P., A. Asimos, J. F. Casella, and C. McMillan. 1986. Inheritance pattern and clinical response to splenectony as a reflection of erythrocyte spectrin deficiency in hereditary spherocytosis. $N$. Engl. J. Med. 315:1579-1583.

45. Becker, P. S., C. M. Cohen, and S. E. Lux. 1986. The effect of mild diamide oxidation on the structure and function of human erythrocyte spectrin. J. Biol. Chem. 261:4620-4628.

46. Greenquist, A. C., S. B. Shohet, and S. E. Bernstein. 1978. Marked reduction of spectrin in hereditary spherocytosis in the common house mouse. Blood. 51:1149-1155.

47. Coetzer, T., and S. S. Zail. 1981. Tryptic digestion of spectrin in variants of hereditary elliptocytosis. J. Clin. Invest. 67:1241-1248.

48. Wolfe, L. C., K. M. John, J. C. Falcone, A. M. Byrne, and S. E. Lux. 1982. A genetic defect in the binding of protein 4.1 to spectrin in a kindred with hereditary spherocytosis. N. Engl. J. Med. 307:13671374.

49. Goodman, S. R., K. A. Shiffer, L. A. Casoria, and M. E. Eyster. 1982. Identification of the molecular defect in the erythrocyte membrane skeleton of some kindreds with hereditary spherocytosis. Blood. 60:772-784. 